\title{
Board 132: Documenting Student Perspectives of Learning While on Co-op
}

\section{Ms. Katherine M Ehlert, Clemson University}

Katherine M. Ehlert is a doctoral student in the Engineering and Science Education department in the College of Engineering, Computing, and Applied Sciences at Clemson University. She earned her BS in Mechanical Engineering from Case Western Reserve University and her MS in Mechanical Engineering focusing on Biomechanics from Cornell University. Prior to her enrollment at Clemson, Katherine worked as a Biomedical Engineering consultant in Philadelphia, PA. Her research interests include identity development through research experiences for engineering students, student pathways to engineering degree completion, and documenting the influence of co-op experiences on academic performance.

\section{Dr. Marisa K. Orr, Clemson University}

Marisa K. Orr is an Assistant Professor in Engineering and Science Education with a joint appointment in the Department of Mechanical Engineering at Clemson University. Her research interests include student persistence and pathways in engineering, gender equity, diversity, and academic policy. Dr. Orr is a recipient of the NSF CAREER Award for her research entitled, "Empowering Students to be Adaptive Decision-Makers." 


\section{MOTIVATION}

Calls for improved educational practices within the field of engineering are focusing around content delivery and not expansion of the content itself. Many educators argue that authentic engineering tasks and prepare students for engineering in the 21st century. Co-operative education (co-op) can provide such experiences. Studies have shown that students who have participated in co-op programs typically graduate with higher GPAs, have an easier time transitioning into full-time work, and begin working at higher starting salaries. Although there are many documented benefits to coop experiences, there is little documented on the ways in which co-op provides these benefits.
METHODS

This will be done using a method that was developed in educational psychology but is relatively unknown in the field of engineering education research: The Q-methodology. The Q-methodology is a quantitative analysis approach that is intended to systematically measure and document perspectives or viewpoints. Twenty-five students will first sort a set of subjective statements related to learning on co-op and then be interviewed to better understand their perspective. Data will be analyzed by grouping participants quantitatively and then qualitatively create descriptive profiles for each finalized group.

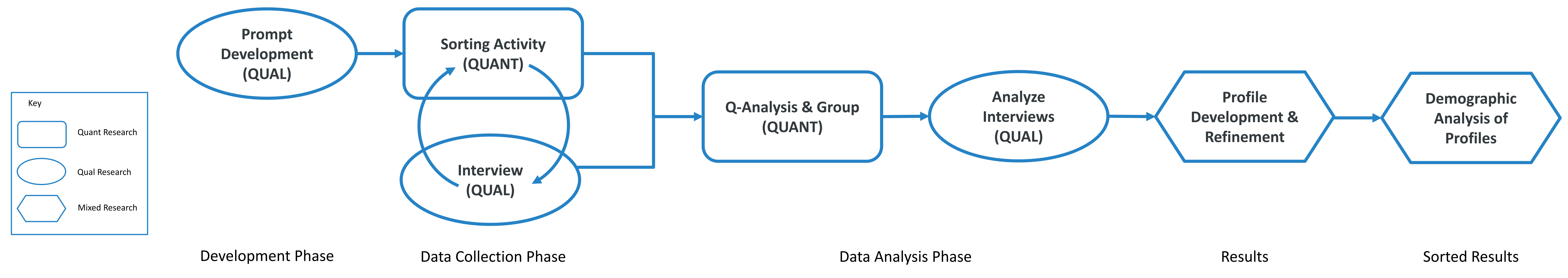

PROMPT DEVELOPMENT

Prompts were modified from Johnston et al. [1] to fit the context of the study. The prompts will parse differences in student perceptions of what was learned and how they learned it during these co-op experiences.

Prompts will be modified by

- Change from third-person language to first-person

- Use student language collected from an exploratory pilot study

- Map prompts to theoretical

frameworks (Experiential Learning Theory [2], Situated Learning [3], Social Cognitive Career Theory [4], and Metacognition [5])
SORTING ACTIVITY

Participants sorted 42 prompts into a quasi-normal distribution (pictured below) on a 7-point scale from Strongly Disagree to Strongly Agree. Prompts will then be assigned numerical values from -3 to +3 . Correlations between participants will be calculated and used to group.

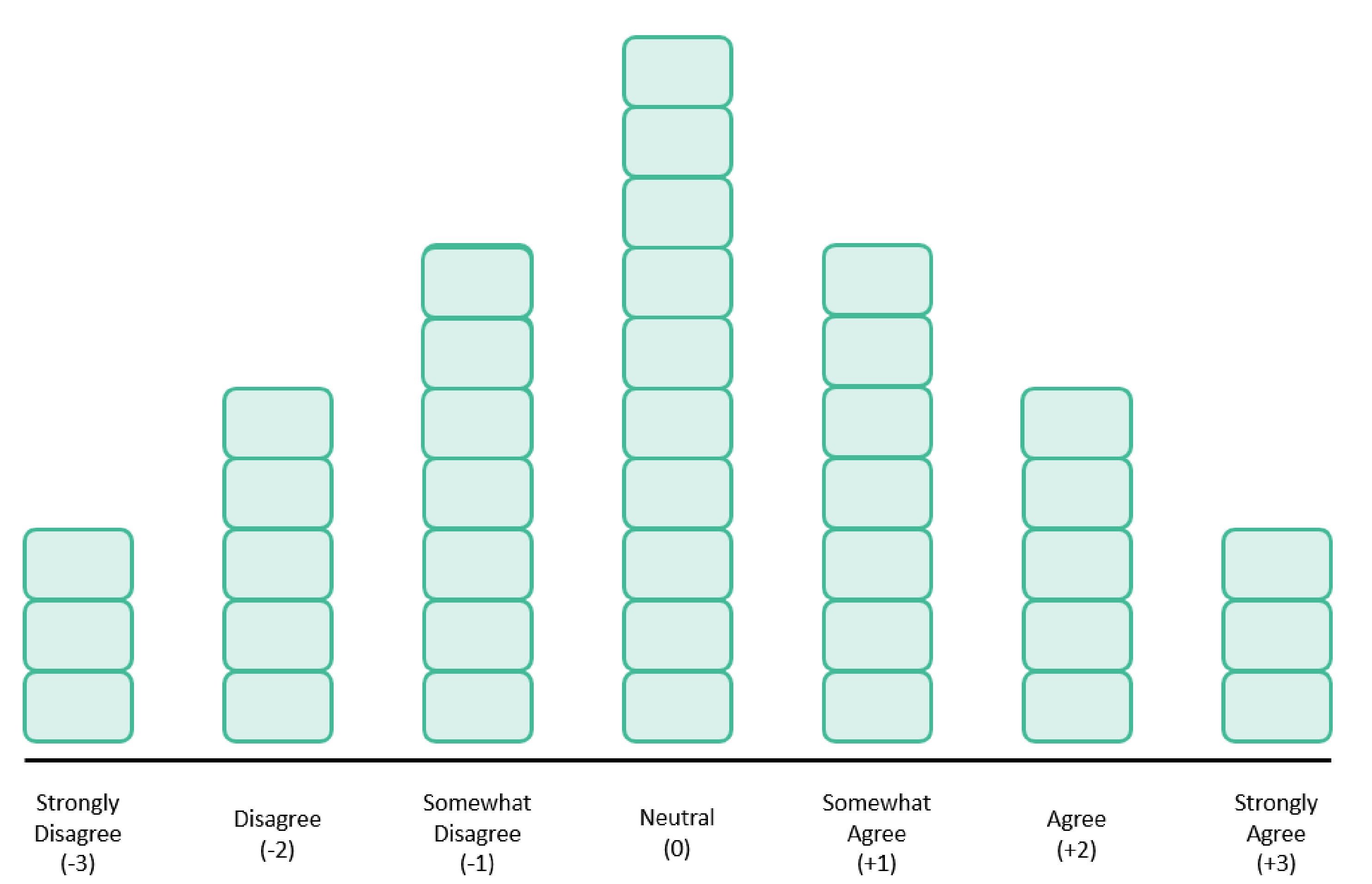

GROUPING USING Q-METHODOLOGY

Correlations between participants will be calculated and a factor analysis will be conducted to determine latent groups of individuals within the sample. Profiles will be developed using the ranked prompts and the interview data.

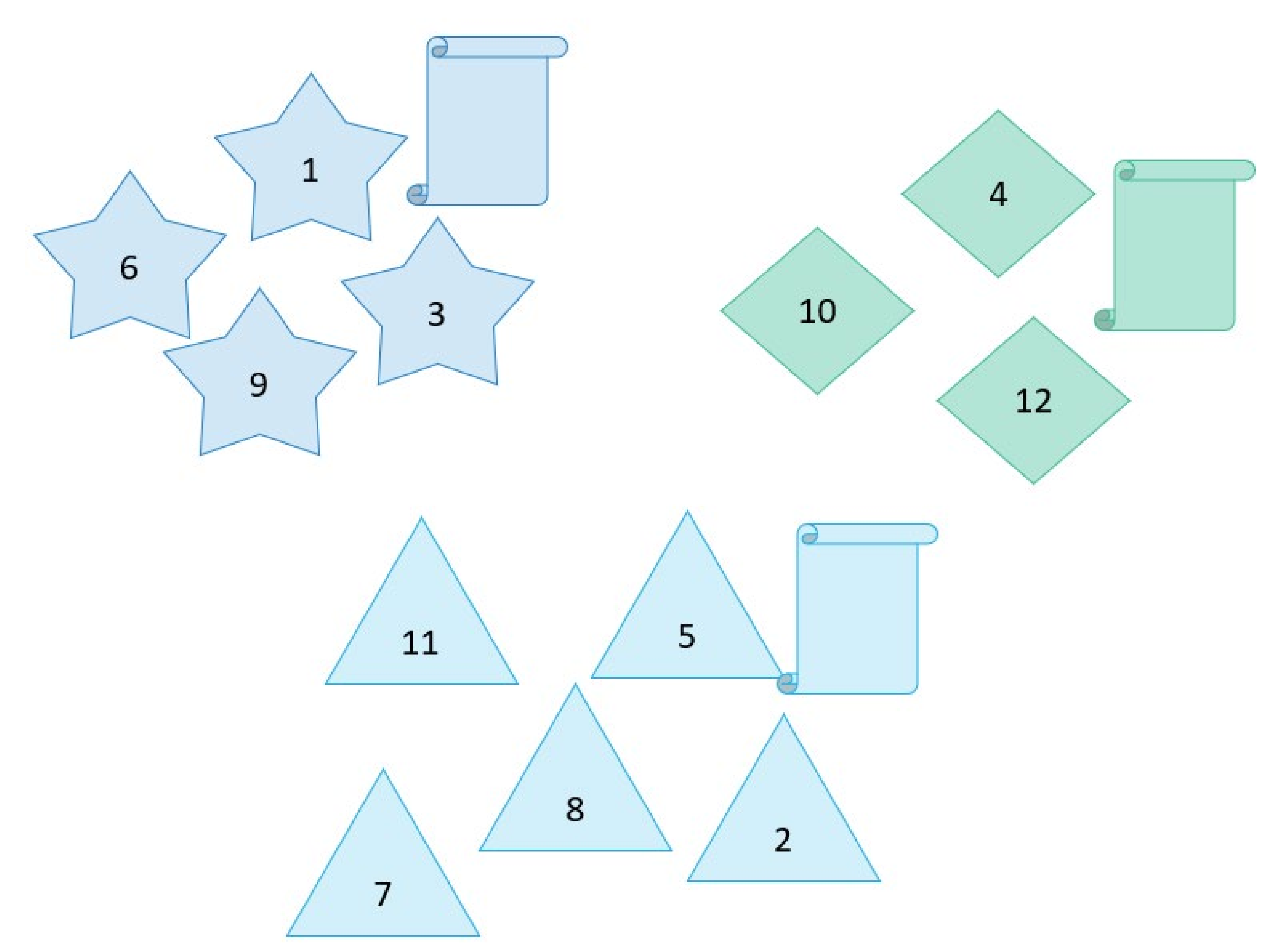

ADDING DEMOGRAPHICS

After groups are finalized and profiles are developed, demographics that are representative of co-op experience will add to the depth of profiles. This will help identify potential influences on student learning.

Demographics will include:

- Major

- Company size

- Number of co-ops at the company

- Number of co-op rotations 